University of Nebraska - Lincoln

DigitalCommons@University of Nebraska - Lincoln

Eileen Hebets Publications

Papers in the Biological Sciences

$4-2010$

Female mate choice based upon male motor performance

John Byers

University of Idaho, jbyers@uidaho.edu

Eileen Hebets

University of Nebraska - Lincoln, ehebets2@unl.edu

Jeffrey Podos

University of Massachusetts, Amherst, jpodos@bio.umass.edu

Follow this and additional works at: https://digitalcommons.unl.edu/bioscihebets

Part of the Behavior and Ethology Commons

Byers, John; Hebets, Eileen; and Podos, Jeffrey, "Female mate choice based upon male motor performance" (2010). Eileen Hebets Publications. 45.

https://digitalcommons.unl.edu/bioscihebets/45

This Article is brought to you for free and open access by the Papers in the Biological Sciences at DigitalCommons@University of Nebraska - Lincoln. It has been accepted for inclusion in Eileen Hebets Publications by an authorized administrator of DigitalCommons@University of Nebraska - Lincoln. 
Published in Animal Behaviour 79:4 (April 2010), pp. 771-778; doi: 10.1016/j.anbehav.2010.01.009

Copyright $\odot 2010$ The Association for the Study of Animal Behaviour; published by Elsevier Ltd. Used by permission.

Submitted October 12, 2009; revised November 19, 2009; accepted January 11, 2010; published online February 19, 2010.

\title{
Female mate choice based upon male motor performance
}

\author{
John Byers, ${ }^{1}$ Eileen Hebets, ${ }^{2}$ and Jeffrey Podos ${ }^{3}$ \\ 1. Department of Biological Sciences, University of Idaho, Moscow, ID 83844-3051, USA \\ 2. School of Biological Sciences, University of Nebraska-Lincoln, Lincoln, NE 68588, USA \\ 3. Department of Biology, University of Massachusetts, Amherst, MA 01003, USA \\ Corresponding author - J. Byers, email jbyers@uidaho.edu
}

\begin{abstract}
Our goal in this essay is to review the hypothesis that females choose mates by the evaluation of male motor performance. We define motor performance as vigor, the ability to perform energetically expensive acts repeatedly, or as skill, the ability to perform difficult motor tasks well. Motor performance reflects most aspects of whole-organism performance that relate to survival, and thus should indicate, more reliably than ornaments do, individual male genetic quality and/or developmental history. Male sexual displays in many animal taxa contain elements of vigor and/or skill, and accumulating evidence suggests that females choose mates in nature based upon their evaluations of male motor performance. We note that male ornaments in many species are accompanied by conspicuous motor display, and we propose that ornaments often arise secondarily as a way to enhance the apparent skill or vigor of male motor performance. More and better methods to measure male vigor and skill are needed, as well as additional studies on the abilities of females to make discriminations of this type.
\end{abstract}

Keywords: female mate choice, male display, motor performance, skill, vigor

Charles Darwin (1859) proposed that many male sexual traits (ornaments and displays) evolve due to sexual selection by female mate choice. In spite of initial resistance to Darwin's proposal, and a subsequent century of limited attention on the topic (reviewed by Cronin 1991), the study of sexual selection currently stands front and centre within the field of animal behavior. Empirical and theoretical work on sexual selection has traditionally focused on male ornaments, most famously the peacock's (Pavo cristatus) tail. Sir Ronald Fisher (1930) developed a verbal model of an evolutionary process by which ornaments could evolve to become exaggerated, in spite of the expectation that such traits reduce the bearer's survival ability. Subsequently, Lande (1981) and Kirkpatrick (1982) developed mathematical models of the Fisher idea, and a vigorous debate in the literature followed on the question of whether ornaments evolve via the Fisher runaway mechanism, which requires a genetic correlation between the magnitude of the male ornament and the magnitude of the female preference, or alternatively whether ornaments evolve as indicators of male breeding value for offspring quality. Critics of the indicator hypothesis noted that the association between male ornament size and male breeding value would tend to decay, but supporters replied that the decay could be avoided if male ornaments were condition dependent (Borgia, 1979; Taylor and Williams, 1981; Pomiankowski and Møller, 1995; Rowe and Houle, 1996; Houle and Kondrashov, 2002). Kotiaho \&
Puurtinen (2007) provide a more complete review of the history of these ideas.

Nevertheless, there now seems to be widespread acceptance that male ornaments are reliable indicators of male breeding value for offspring quality, and that the primary question about female mate choice concerns the origins and maintenance of preferences that result in the evolution of exaggerated male ornaments. For example, in a terms-definition box in a recent issue of Trends in Ecology and Evolution, Tomkins et al. (2004, page 323) defined good genes as "models of sexual selection that assume that extreme ornaments indicate the genetic quality of the bearer, defined as breeding value for fitness." Or, consider Kirkpatrick's (1987, page 45) widely cited formulation: "Sexual selection by female choice involves two characters, a male secondary sexual trait and a female mating preference." Data supporting this model, however, are incomplete. Many researchers have indeed shown that females often prefer males with exaggerated ornaments (Andersson, 1989; Hill, 1990; Møller, 1991), and some studies have reported data on sire effects (i.e. showing that males with more elaborate ornaments sire offspring with superior health, survival or developmental profiles; Petrie 1994). But, despite keen interest on the topic for more than a quarter century, no published study has put these two lines of evidence together for a single species, to show that the free choices of females in nature create stabilizing or directional selection for high values of male ornament expression, and to show simultaneously that offspring quality is associated with 
the selected values of sire ornament expression.

Stepping back, the foundation for a broader view of sexual selection by female choice was put forward 9 years before the Lande paper, by Robert Trivers, who wrote: "As in other aspects of sexual selection, the degree of male investment in the offspring is important and should affect the criteria of female choice. Where the male invests little or nothing beyond his sex cells, the female has only to decide which male offers the ideal genetic material for her offspring..." (Trivers 1972, page 167). This view looks beyond ornaments per se; it predicts that sexual selection by female choice should occur wherever there is asymmetry in parental investment, and that females should evolve the ability to discriminate among potential mates, using whatever information is available. Consider the situation in mammals, where asymmetry in parental investment is extreme. With few exceptions (e.g. Bradbury 1977), male mammals do not possess sexual ornaments analogous to the elongated tail feathers or brightly colored plumage of birds. In the few mammalian species in which males have some conspicuous coloration (Fernandez \& Morris 2007), it is doubtful that the coloration constitutes a character that is opposed by natural selection. Many male mammals do possess characters that are associated with intrasexual selection, such as weapons (Emlen 2008), large body sizes and pugnacious dispositions, but they do not possess nonutilitarian ornaments that serve female choice.

The virtual absence of male ornaments in mammals forces one of two conclusions: either sexual selection by female choice does not occur in mammals, or alternatively, it does occur, but the criteria by which females evaluate males involve something other than ornaments. In this article, we review the evidence that, across a wide range of taxa, females evaluate males largely based on male motor performance, especially within mating displays. This hypothesis has numerous precedents (e.g. Ryan and Keddy-Hector, 1992; Rowe and Houle, 1996; Irschick et al., 2007) but remains largely unappreciated in the broader literature on sexual selection. We also examine the idea that motor performance provides particularly reliable information about male genetic quality, condition and developmental history, superior to information that could be derived from ornaments alone.

\section{Motor Performance as Vigor}

Motor performance as we define it includes two somewhat overlapping aspects of behavior. The first is vigor, a term used by Darwin $(1859,1871)$. Vigor is an individual's ability to perform energetically expensive motor acts repeatedly. Consider the pronghorn, Antilocapra americana. Within this species, the mate-sampling strategy of females forces males into many energetically demanding acts of harem defense (Byers et al. 1994), and the males that sire the greatest number of offspring are typically those that are able to defend a harem for many successive days during rut (Byers 1997). Moreover, this female mate sampling is costly to females (Byers et al., 2005, 2006), and nearly all females each year converge in their choices, without copying, on a small subset of males in the population. The males in this subset, all having demonstrated vigor by their ability to defend a harem over many days, provide superior breeding value for offspring survival (Byers \& W Waits 2006). Other examples of traits indicative of vigor that females might use to evaluate males include the leaping and the climbing and diving displays of snipe, genus Capella (Sutton 1981), the diving and shuttle displays of several species of hummingbirds (Stiles 1982), the leaping displays of blueblack grassquits, Volatinia jacarina (Costa and Macedo, 2005; Aguilar et al., 2008), wing-clapping displays of flappet larks, Mirafra rufocinnamomea (Norberg 1991), the chasing behavior of house flies
Fannia canicularis (Land \& Collett 1974), the leg-waving displays of many wolf spiders (Hebets \& Uetz 1999) and the energetically expensive waving of the enlarged cheliped in fiddler crabs, genus Uca (Salmon et al., 1978; Matsumasa and Murai, 2005). Additional examples include the lengthy bouts of flying in some male bird displays (Mather \& Robertson 1992), the sustained, energetically expensive vocalizations of many anuran amphibians (Prestwich, 1994; Welch et al., 1998) and of some ungulates (Wyman et al. 2008), sustained stridulation in some orthoptera (Hedrick, 1986; Prestwich, 1994; Prestwich and O'Sullivan, 2005), sustained flashing displays of fireflies (Lewis \& Cratsley 2008) and persistence on leks by displaying males (Leuthold, 1966; Vehrencamp et al., 1989; Deutsch, 1994; Isvaran and Jhala, 2000). Indeed, one of the most striking aspects of many male mating displays is their repetitive nature. Certainly, the vigorous repetition of a display can serve other functions, such as repelling rivals, or simply increasing the likelihood of attracting a female, but to the extent that repetition is energetically costly, or to the extent that repetition exposes the signaler to danger or risk of retaliation, it becomes a way in which the quality of males can be compared. In addition, females may be able to assess vigor by observing male fighting and similar forms of competition, by indirectly detecting the outcome of male-male competition, or by inciting male competition and selecting the winner (Cox and LeBoeuf, 1977; Byers et al., 1994; Bro-Jorgensen, 2002). In many lek-breeding species, females prefer to mate with males that occupy territories at the spatial centre of the lek (Hoglund and Lundberg, 1987; Apollonio et al., 1992; Kokko et al., 1999; Isvaran and Jhala, 2000; Bro-Jorgensen and Durant, 2003). Here, to the extent that males compete for central locations, the female preference is for vigor.

Studies on wolf spiders provide multiple lines of support for the hypothesis that display vigor is used in mate choice. Mature male Hygrolycosa rubrofasciata court females by striking their abdomens against the substrate (typically dry leaves) in an action termed "drumming." Drumming increases an individual's metabolic rate 22 fold over resting metabolic rate (Kotiaho et al. 1998b), and is condition dependent (Mappes et al. 1996). Males with high drumming rates survive better in both laboratory and field conditions (Mappes et al., 1996; Kotiaho et al., 1999), and have superior mobility and the ability to evade predators (Lindström et al. 2006). Female H. rubrosasciata prefer the sound of drums of longer duration and males that drum more actively (Kotiaho et al., 1998a; Parri et al., 2002).

Recently, courtship intensity or vigor was shown to influence female mate choice in other wolf spider species. Nutritional enrichment enhanced courtship intensity in Pardosa prativaga, and nutrient-enriched males experienced higher mating success (Lomborg \& Toft 2009). Similarly, P. milvina males in better condition court at higher rates and survive predation better than do males in poor condition (Hoefler et al. 2008), and females prefer to mate with males performing more body shakes and leg raises (Rypstra et al. 2003). Male courtship rate in P. milvina is repeatable for most male-female pairings, and females that mate with males with high courtship rates tend to produce more offspring, which in turn emerge sooner and show greater probabilities of survival (Hoefler et al. 2009). Schizocosa wolf spiders are well known for their elaborate courtship dances and associated ornaments (Hebets and Uetz, 2000; Stratton, 2005; Framenau and Hebets, 2007). In S. ocreata, multiple aspects of courtship signaling rate and duration are important in female mate choice (Delaney et al., 2007; Gibson and Uetz, 2008). In S. uetzi, the rate of male leg raises influences female mate choice (Shamble et al. 2009). Although S. uetzi males possess foreleg ornamentation that is condition dependent, female choice appears to be based on courtship rate, irrespective of foreleg ornamentation (Shamble et al. 2009). 
Results from studies on Photinus beetles parallel those from studies of wolf spiders. In both field observations and photic playback experiments, female Photinus choose males that display higher flash pulse rates and durations, which in turn might be limited by male vigor (Demary et al., 2006; Lewis and Cratsley, 2008).

Vigor should provide a highly reliable indicator of male quality, for at least two reasons. First, vigor cannot be faked, as may be possible for an ornament; vigor cannot be decoupled from overall organism performance. Second, vigor is a summed expression of a male's near-complete if not entire functional genome, and thus captures myriad aspects of organism performance, such as immune function, parasitism profile, limb proportions, locomotor efficiency, gut anatomy and digestive efficiency, motivational system and behavioral efficiency, and growth and developmental history. All of these factors listed above shape display vigor in a manner that is independent of the receiver. Display vigor may also be affected by receiver-dependent costs, such as increased probability of retribution from other males, or increased exposure to predators (Searcy \& Nowicki 2005).

\section{Motor Performance as Skill}

The second aspect of male motor performance that females might use when comparing prospective mates is the skill with which an individual performs a challenging action, which could be a single motor pattern or a linked series of motor patterns. A challenging action is one that requires a degree of precision in the activation and coordination of motor units that is greater than that needed for everyday activities or that is close to the limit of production possibilities imposed by an animal's anatomy and physiology. Motor skill and performance abilities are regularly considered in the study of behaviors that are linked to survival, such as feeding or locomotion. In contrast, their impact is considered only rarely in the study of sexual selection and animal signals.

We suggest that skill in the performance of challenging actions is probably equivalent or perhaps better than vigor as an indicator of overall organism performance. In addition to general health, skill necessarily reflects musculoskeletal, nervous and sensory system construction and function, and may thus be a particularly reliable indicator of developmental stability. Nowicki et al. (1998) hypothesized that one kind of behavioral display, birdsong, should provide a particularly reliable indicator of male quality, because the development of brain nuclei that constitutes song learning occurs when young birds are energetically and nutritionally challenged. Support for this "developmental stress" hypothesis appeared in a number of studies (reviewed by Podos et al. 2009). For example, Nowicki et al. (2002) showed that swamp sparrows, Melospiza georgiana, partially deprived of food during early life developed smaller brains, smaller song control brain areas and reduced song learning, as compared to control birds. In a parallel example, it is now established that human children born prematurely tend to exhibit lasting deficits in sensory-motor performance (Foreman et al. 1997).

Is it reasonable to assume that animals can perceive differences between conspecifics in the skill of their motor performances? We suggest that it is, and that animals probably have underappreciated perceptual sensitivities in this arena. Consider an example from our own experiences: almost every adult human can run a short distance, leap in a forward arc, land on one foot, and continue running. However, only a few adults, who we call dancers, can execute this motion in a way that we perceive as beautiful. Additionally, humans easily perceive performance differences between professional dancers, the actions of which must be nearly identical yet still readily distinguishable. Humans also routinely make what must be very fine discriminations among the motor performances of musicians and athletes. Humans can even detect differences in dance quality that are correlated with the degree of fluctuating asymmetry of the dancer (Brown et al. 2005). It is improbable that humans are the only animal species with this kind of perceptual sensitivity.

Sexual selection theory predicts that females choosing mates should evolve strong discrimination abilities that allow them to discern males with the most elaborate or intricate sexual traits (Trivers 1972) and to resist the courtship efforts of males that do not quite make the grade (Holland \& Rice 1998). Many studies on sexual selection have shown that females can indeed discern slight differences between exaggerated male ornamental variations. Yet we have few data that speak to this possibility for motor performance, undoubtedly because of the difficulty in quantifying both the variation in male motor displays and the variation in female responses. With regard to visual discrimination, our understanding of perceptual abilities might be guided by analogous data on predatory behavior in mammals. Numerous accounts of predators that hunt mobile prey describe a two-stage process in which the predator first rushes a group of prey and then selects a single individual to pursue (Schaller, 1972; Holekamp et al., 1997; Peterson and Ciucci, 2003). Holekamp et al. (1997, page 4) described this hunting method in spotted hyenas, Crocuta crocuta, as follows: "The hunting methods utilized by our study animals matched those described previously by Kruuk (1972), Mills (1990) and Cooper (1990). That is, our study animals typically first rushed a group of prey animals, stood briefly to observe the prey animals' locomotor behavior, selected one target individual, then chased that individual down over distances ranging from $75 \mathrm{~m}$ to $4 \mathrm{~km}$." Usually, human observers are unable to detect the subtle deficit that the predators identify, and the human observers tend to describe the perceptual ability of the predators as "uncanny" (Holekamp et al. 1997). The elaborate stotting that prey such as Thomson's gazelles, Gazella thomsoni, perform at the beginning of a predator attack suggests that the predators are capable of detecting slight differences in the motor performance of prey (FitzGibbon \& Fanshawe 1988). It is also well known that predators efficiently identify weak, injured or sick prey (Mills, 1990; Quinn and Cresswell, 2004; Martin et al., 2006; Wright et al., 2006). In summary, natural selection on predators has probably enhanced animals' ability to detect subtle differences in the motor performance of potential prey. We suggest that it is similarly likely that sexual selection has created parallel capabilities in females to detect subtle differences in the motor performance of potential mates. In the remainder of our essay we ask what aspects of performance could serve as reliable indicators of skill, reviewing relevant data in birds, mammals, and arthropods.

\section{Motor Skill in Bird Displays}

A significant body of research has focused on the production, perception, and evolution of vocal displays in birds. Studies of sexual selection on birdsong have traditionally focused on the hypothesis that song complexity, especially repertoire size, is a primary guide for female choice. There is significant disagreement, however, about the extent to which this hypothesis is supported by available evidence, in spite of several compelling data sets correlating repertoire size and male mating success (Hasselquist et al., 1996; Reid et al., 2004). A recent review by Byers $\&$ Kroodsma (2009), for instance, questions the biological validity of assays used to infer female preferences for large repertoires, and also notes that small repertoires persist in many songbird lineages, with corroborating evidence in the evolution of some clades for repertoire reductions rather than expansions. An alternative 
set of characteristics to which females may attend more generally, independent of repertoire size, concerns male vocal skill, as reflected, for example, in the production of particular syllables and phrases and in the consistency with which vocal elements are repeated across renditions (Lambrechts, 1996; Gil and Gahr, 2002; Podos et al., 2009). Studies of vocal mechanics during the last 25 years have illustrated that song production by male birds is intrinsically challenging, involving the simultaneous control and coordination of breathing, syrinx modulations (the left and right sides having separate innervations) and vocal tract modulations including those of the trachea, mandible and oropharyngeal cavity (Nowicki, 1987; Podos and Nowicki, 2004; Suthers, 2004; Riede et al., 2006). Even acoustically simple songs, such as that of the northern cardinal, Cardinalis cardinalis, are appropriately regarded, given the complexity of their production mechanism, as an "extraordinary feat of virtuosity" (Suthers 2004). Mechanical limits on vocal production are particularly evident when birds sing high-bandwidth frequency sweeps that are packed together in rapid trills. There is a performance trade-off between these two song components (Podos, 1996, 1997): at some limit, a bird cannot sing faster trills without truncating bandwidth or cannot increase bandwidth without slowing the trill rate. Other vocal components that may reveal male vocal skill include the production of constant note frequency ratios (Christie et al. 2004), of song repertoires with high proportions of trilled songs (Schmidt et al. 2008), and of high-frequency notes with consistency (Byers 2007).

Some evidence suggests that birds can discriminate among the song components that reflect vocal skill. For example, female canaries, Serinus canaria (Draganoiu et al. 2002) and swamp sparrows (Ballentine et al. 2004) prefer (laboratory copulation solicitation display tests) trills that are close to mechanical performance limits; male chestnut-sided warblers, Dendroica pensylvanica, that sing high-frequency notes with greater consistency attract more extrapair mates (Byers 2007); male chickadees, Poecile atricapillus, with the most consistent internote ratios are most dominant at feeders (Christie et al. 2004); male blue tits, Cyanistes caeruleus, with highly consistent intersong intervals tend to sire more offspring (Poesel et al. 2001); and territorial male nightingales, Luscinia megarhynchos, are repelled more effectively by playback of song bouts that include higher proportions of trilled songs (Schmidt et al. 2008). In satin bowerbirds, Ptilonorhynchus violaceus, male attractiveness to females is strongly correlated with the number of other species' songs that the male mimics, and with the accuracy of the mimetic copies (Coleman et al. 2007). We suggest that there are probably many other aspects of birdsong that represent "Olympian" performances, and in which relevant variation among singers is defined by how closely individuals can approach the physically maximum possible performance. Indeed, the prevalence of sensorimotor song development in birds may be a reflection of the fact that song is physically challenging to produce, and that practice is required to enable accurate model reproduction (Podos et al. 2009).

In the New World manakins (Pipridae), males of many species produce non-vocal courtship sounds by extraordinary movements of their wings (Bostwick and Prum, 2003; Bostwick and Prum, 2005). Several of these sounds are produced as birds slap the dorsal surfaces of their wings together at very high repetition rates, close to the contraction speed limits of vertebrate muscle. Males often perform these movements in the midst of horizontal or vertical leaps. It seems likely that these amazing motor performances represent the outcome of an evolutionary process in which females chose males based upon their skill in performing elaborate courtship leaps (Prum 1997). We suggest that birdsong represents a similarly derived state of advanced motor performance. However, because the motor acts in song are of smaller amplitude and are largely contained inside the bird, their difficulty is not as readily apparent.

Males of many bird species court females, as do wing-sonating manakins, using whole-body acrobatics. Display flights are especially common. In his review of the display flights of snipe, Sutton (1981, page 474) wrote: "All but one of the 13 currently recognized species of the scolopacid genus Capella display in the air during courtship, though aerial display is not restricted to the breeding season. Display flights are accompanied by hooting, bleating, neighing, or whinnying sounds that are widely believed to be non-vocal and that almost certainly are produced by vibration of some or all of the tail feathers." Such non-vocal sounds are produced repeatedly as individuals make long series of climbs and dives. During dives, sound amplitude increases with dive speed, reaching a sudden crescendo as the bird pulls out of the dive to climb. Even more spectacular U-shaped dive displays occur in some hummingbird species (Johnsgard 1997). Of Allen's hummingbird, Selasphorus sasin, and Anna's hummingbird, Calypte anna, Larimer \& Dudley (1995, page 1064) wrote: “... the display usually begins with a long steep dive initiated $20-35 \mathrm{~m}$ above a conspecific bird. When the diving bird is about $1 \mathrm{~m}$ of the display target and moving probably at maximal velocity, an abrupt pullout ensues during which radial accelerations must be substantial." Larimer \& Dudley (1995) calculated that the birds dive at a velocity of $17 \mathrm{~m} / \mathrm{s}$, and make U-turns of radius 3-4 m at the bottom of the dive, resulting in radial accelerations of 70$100 \mathrm{~m} / \mathrm{s}^{2}$, with forces on the wings that are up to 10 times body mass. Recently, Clark (2009) showed that the courtship dive of Anna's hummingbirds has a peak average velocity of $27.3 \mathrm{~m} / \mathrm{s}$, the highest known length-specific velocity of any vertebrate. During the pull up from the dive, males experience centripetal accelerations nine times that of gravitational acceleration; taken together, these values sug gest that male courtship dives reveal the physical performance limits of individual males (Clark 2009). These birds also capitalize on the high forces at maximum dive velocity to produce high-pitched tones by vibrations of their tail feathers (Clark \& Feo 2008). Acrobatic flight displays occur in many of the shorebirds, gulls and alcids (Charadrii); in this suborder, the presence of acrobatic displays is associated with evolutionary reduction in male size, presumably because lower mass permits greater performance in difficult flight maneuvers (Székely et al. 2000).

Like some manakins, hummingbirds and snipe, male flappet larks produce non-vocal sounds during flight displays (Norberg 1991). Displaying males produce these sounds by slapping the ventral surfaces of the wings together while accelerating upward in flight at a steep angle. Without changing the amplitude of wing beats, displaying males increase wing beat frequency from $11 / \mathrm{s}$ to $24 / s$, which requires a doubling of power consumption compared to normal flight. Slow-motion analysis of the displays of blue-black grassquits reveals that the "jumps" of males are actually short, almost vertical flights, in which, in some birds, the male's wings meet dorsally to produce short clicks analogous to those produced by manakins (J. Podos \& R. H. Macedo, unpublished data).

In addition to acrobatic aerial displays, modified walking or hopping, sometimes combined with short flights, occurs in the display actions of many birds. These actions often look unnatural because of the extremely rapid motions that they entail. For example, red-capped manakin, Pipra mentalis, male courtship involves backward "slides" along a branch by tiny, imperceptibly fast movements of the male's feet (Prum 1990). Other manakin males incorporate very rapid short flights and acrobatic hops in their displays to females, often occurring in synchrony with sonation (Prum and Johnson, 1987; Thery, 1990; Bostwick and Prum, 2003). High-speed hops, pivots and glides and other unusual movements occur in the 
courtship displays of males in many species of the birds of paradise (Aves: Paradisaeidae). For example, Scholes (2008, page 498) wrote that courtship movements of males in the genus Parotia include "(1) horizontal perch pivot; (2) sidle/head tilting; (3) hop/charge; (4) stand/hops and shake; (5) the various ballerina dance phases; and (6) dance/bounce. There are four distinct ballerina dance phases...." In addition to highly acrobatic and rapid movements in courtship displays, males in the manakins and in the birds of paradise often have brightly colored, highly modified plumage that certainly falls into the class of characters that are commonly called ornaments. We suggest that modified plumage in the dancing manakins and birds of paradise, and probably in many other ornamented species, has arisen as a secondary adaptation to enhance the visual stimulus value, or the apparent quality of motor performance, of male display.

\section{Motor Skill in Mammal Displays}

There is growing evidence that mammals are able to detect subtle differences in the motor performances of conspecifics. Pelletier et al. (2004) found that bighorn rams, Ovis canadensis, that were chemically immobilized by researchers for radio-collaring suffered almost immediate rank challenges upon returning to the ram group, even though the researchers could detect no movement deficits. Pelletier et al. (page 1165) concluded that "Subordinate rams appeared to detect some subtle 'vulnerabilities' in captured rams just after the release...." It seems likely that such perceptual capabilities are enhanced by selection for distinguishing among potential mates or rivals. Stereotyped acrobatic displays by males have been described infrequently for mammals, but it is unclear whether this is because such displays in mammals are uncommon, or because descriptions of what female mammals do in nature when they choose mates are so rare. In the pronghorn rut, males sometimes perform an act, called a circle chase (Byers 1997), that appears to be a display of speed and agility. In a circle chase, a male rushes at a single female in his harem. The female runs away but not in a clear attempt to escape. She runs in tight loops of about 50-70 m radius, close to the harem, frequently changing direction in fast dodging turns, with the male following closely (usually within 1-2 m) behind, matching every direction change. The chased female does not run at top speed, and the male does not attempt to close the gap. Other females in the harem commonly watch the circle chase. The chase ends after about 30-60 s, and the female rejoins the harem. It is not clear whether the male initiates the circle chase or whether he responds to a subtle movement of a female in his harem. The circle chase clearly has the potential to act as a male display of running ability and agility.

In other mammals, the actions of females at the moment of copulation seem to act as tests of male agility. Bison, Bison bison, females commonly run from the tending bull at the moment that he achieves intromission, and males often maintain intromission until ejaculation by running behind the female on their hindlegs for up to $100 \mathrm{~m}$ (Lott 2002). Even more spectacular running copulations occur in bighorn sheep (Hogg \& Forbes 1997). Coursing rams (Hogg 1984) rush a tending ram and the ewe that he is guarding. If the ewe runs, the coursing rams pursue, leap onto the ewe's back and copulate with her while she runs. This male tactic is unusually successful (Hogg \& Forbes 1997) and clearly favors the success of males that demonstrate extreme agility. Male sac-winged bats, Saccopteryx bilineata, attract and defend harems of females with conspicuous and energetically expensive hovering display flights (Voigt et al. 2001). Males are smaller than females in this species, and may be so partly because natural selection on small size favors improved flight maneuverability (Voigt et al. 2005). This interpretation must be viewed with caution, how- ever, because males are smaller than females in a majority of bat species that feature multiple mating systems; further information on the relative contributions of multiple selective pressures on sexual size dimorphism in bats awaits a comparative study, analogous to that which has been conducted on shorebirds (Székely et al. 2000).

In many mammals, intrasexual competition among males is pronounced, resulting in substantial sexual dimorphism in body size and weapons. This has led some to conclude that intrasexual competition in male mammals precludes the opportunity for sexual selection by female choice (Clutton-Brock \& McAuliffe 2009). However, to the extent that the outcome of competition among male mammals is governed by vigor or skill, female mammals can select for motor performance by preferring and choosing the winners of male-male competition. In pronghorn (Byers et al., 1994; Byers, 1997), females at estrus sometimes incite fights between males. The inciting female appears to watch these fights closely and then immediately mates with the winner. In some mammals that breed on leks, males compete to occupy spatially central territories; females can choose males that have won this competition simply by exerting a preference to mate on central territories.

In many mammals and other taxa, it may be difficult or im possible in practice to disentangle the effects of male-male com petition and female choice for male motor performance as determinants of male mating success. However, we suggest that more successful discriminations than one might expect will be brought to light with further descriptions of the sampling behavior of individual females in nature before and at sexual receptivity. A general weakness of sexual selection work to date, especially in mammals, is that there are few studies on the unrestrained behavior of individual females in nature as they sample and choose mates.

\section{Motor Skill in Arthropods}

Courtship displays in dipteran flies often involve swarming dances, complex aerial pursuits and/or elaborate displays on the ground (Downes 1969). Long-legged flies in the family Dolichopodidae show courtship displays that involve many complex flight maneuvers (Land and Collett, 1974; Land, 1993; Zimmer et al., 2003). Lunau (1992) suggested that the physiological constitution (speed or agility) of the males may be indicated through these dy namic courtship movements. In the copepod Temora longicornis, females cruise through the water leaving a chemical trail that is detectable by males for up to $10 \mathrm{~s}$. Upon encountering a trail, males follow and attempt to catch the female (Doall et al., 1998; Weissburg et al., 1998). In this scenario, it seems likely that directional selection for male skill, supported by superior sensory and locomotory systems, would be favored by sexual selection.

Fiddler crabs provide a rare instance in which male display characteristics and female choice have been studied predominantly in the field under natural conditions. Males in the genus Uca produce species-specific visual and acoustical displays that involve body lifts, leg extensions, and movements of both major and minor chela (Salmon et al. 1978). In Uca perplexa, video analyses revealed that subtle differences in male movements influence female choice. Males that were visited by females in the field completed the downward component of the chela wave more rapidly than their neighbors, and the interval between the end of one wave and the start of the next was shorter (Backwell et al. 1998). A subsequent study found similar results: the waves of males that were visited by females were distinct from those that females passed by (Murai $\&$ Backwell 2006). These studies suggest that females are not only capable of detecting subtle differences in male courtship skill, but that they base their reproductive decisions upon such subtleties. 


\section{Predictions}

Courtship displays that involve strenuous and/or skilled motor acts are common in animals. We predict that significant variation exists among males in the deployment of these displays, with respect to vigor or skill, or both. We also predict that aspects of display performance will correlate with aspects of male quality (e.g. current condition, developmental history, immune function, breeding value for offspring performance), or with direct contributions that males make to the female. Furthermore, as the intended receivers of most courtship displays, we expect that females are capable of discerning slight differences in male display performance and, most importantly, we predict that female mate choice decisions are based upon these subtle differences in the performance of male courtship displays.

In species where motor performance is crucial for survival, we predict that male displays will reflect these motor challenges, not only in overall display complexity, but also in their specific display components. For example, we expect broad patterns of display complexity to correlate with natural history, such as is seen in spiders where the most elaborate courtship displays are found in taxa that are also active hunters (i.e. jumping spiders, lynx spiders, wolf spiders), while those adopting sit-and-wait strategies tend to have less complex courtship displays (Foelix 1996). We also expect that specific courtship elements will often mimic movements essential to an individual's motor repertoire; for example, flying animals that rely on speed and agility for either prey capture or predator evasion will incorporate flight speed and maneuverability into their courtship displays as a reflection of their motor performance. Finally, for taxa in which motor performances are produced in tandem with the presentation of ornaments, we predict that motor performances will be found to have evolved first, and that the subsequent elaboration of ornaments may have served to enhance the visual appearance of display performances. Testing many of these predictions will require detailed analyses of display structure, and such detailed analysis is becoming more and more feasible with the development of new technologies. Phylogenetic comparative analysis will also aid in the reconstruction of pathways of ornament and display evolution.

\section{Summary}

We suggest that sexual selection by female choice for male motor performance is more common than currently appreciated. Motor performance refers to vigor and/or skill. Vigor and skill are closely linked to whole-organism performance, and thus should be especially useful indicators of individual genetic load (Rowe and Houle, 1996; Whitlock and Agrawal, 2009), individual developmental history, and current health and condition. These are testable hypotheses. Vigor and skill are certainly more difficult to document and measure than are ornaments, but modern technology (e.g. highspeed videography, acoustic analyses, telemetered EMG) can help overcome this limitation. It seems likely that females are selected to be able to perceive slight differences in motor performance of conspecific males, although the degree of perceptual sensitivity is at this point unknown. We also predict that in many species, the ornaments that troubled Darwin and that many researchers now believe to be the target of sexual selection by female choice will be found to have evolved as secondary enhancers of male motor display.

Acknowledgments - We gratefully acknowledge the National Science Foundation (NSF) grants that supported the production of this manuscript: NSF 0738012 to J.B., NSF 0934990 to E.H., and NSF 0347291 to J.P. We also thank Mike Beecher, Bill Searcy, and an anonymous referee for Animal Behaviour who helped us to sharpen our argument.

\section{References}

Aguilar et al., $2008 \bullet$ T. M. Aguilar, R. Maia, E. S. A. Santos, and R. H. Macedo, Parasite levels in blue-black grassquits correlate with male displays but not female mate preference, Behavioral Ecology 19 (2008), pp. 292-301.

Andersson, $1989 \bullet$ S. Andersson, Sexual selection and cues for female choice in leks of Jackson's widowbird Euplectes jacksoni, Behavioral Ecology and Sociobiology 25 (1989), pp. 403-410.

Apollonio et al., $1992 \bullet$ M. Apollonio, M. Festa-Bianchet, F. Mari, S. Mattioli, and B. Sarno, To lek or not to lek: mating strategies of male fallow deer, Behavioral Ecology 3 (1992), pp. 25-31.

Backwell et al., $1998 \bullet$ P. Backwell, M. Jennions, N. Passmore, and J. Christy, Syn chronized courtship in fiddler crabs, Nature 391 (1998), pp. 31-32.

Ballentine et al., $2004 \bullet$ B. Ballentine, J. Hyman, and S. Nowicki, Vocal perfor mance influences female response to male bird song: an experimental test, Be havioral Ecology 15 (2004), pp. 163-168.

Borgia, $1979 \bullet$ G. Borgia, Sexual selection and the evolution of mating systems. In M. S. Blum and N. A. Blum, editors, Sexual Selection and Reproductive Competition in Insects, Academic Press, New York (1979), pp. 19-80.

Bostwick and Prum, $2003 \bullet$ K. S. Bostwick and R. O. Prum, High-speed video analysis of wing-snapping in two manakin clades (Pipridae: Aves), Journal of Experimental Biology 206 (2003), pp. 3693-3706.

Bostwick and Prum, $2005 \bullet$ K. S. Bostwick and R. O. Prum, Courting bird sings with stridulating wing feathers, Science 309 (2005), p. 736.

Bradbury, $1977 \bullet$ J. W. Bradbury, Lek mating behavior in hammer-headed bat, Zeitschrift für Tierpsychologie 45 (1977), pp. 225-255.

Bro-Jorgensen, $2002 \bullet J$ J Bro-Jorgensen, Overt female mate competition and pref erence for central males in a lekking antelope, Proceedings of the National Acad emy of Sciences, U. S. A. 99 (2002), pp. 9290-9293.

Bro-Jorgensen and Durant, $2003 \bullet \mathrm{J}$. Bro-Jorgensen and S. M. Durant, Mating strategies of topi bulls: getting in the centre of attention, Animal Behaviour 65 (2003), pp. 585-594.

Brown et al., 2005 • W. M. Brown, L. Cronk, K. Grochow, A. Jacobson, C. K. Liu, Z. Popovic, and R. Trivers, Dance reveals symmetry especially in young men, Nature 438 (2005), pp. 1148-1150.

Byers, $2007 \bullet$ B. E. Byers, Extrapair paternity in chestnut-sided warblers is cor related with consistent vocal performance, Behavioral Ecology 18 (2007), pp 130-136.

Byers and Kroodsma, $2009 \bullet$ B. E. Byers and D. E. Kroodsma, Female mate choice and songbird song repertoires, Animal Behaviour 77 (2009), pp. 13-22.

Byers, $1997 \bullet J$ J A. Byers, American Pronghorn. Social Adaptations and the Ghosts of Predators Past, University of Chicago Press, Chicago (1997).

Byers and Waits, $2006 \bullet \mathrm{J}$. A. Byers and L. Waits, Good genes sexual selection in nature, Proceedings of the National Academy of Sciences, U. S. A. 103 (2006), pp. $16343-16345$.

Byers et al., $1994 \bullet$ J. A. Byers, J. D. Moodie, and N. Hall, Pronghorn females choose vigorous mates, Animal Behaviour 47 (1994), pp. 33-43.

Byers et al., $2005 \bullet$ J. A. Byers, P. A. Wiseman, L. Jones, and T. J. Roffe, A large cost of female mate sampling in pronghorn, American Naturalist 166 (2005), pp. 661-668.

Byers et al., $2006 \bullet$ J. A. Byers, A. A. Byers, and S. J. Dunn, A dry summer dimin ishes mate search effort by pronghorn females: evidence for a significant cost of mate search, Ethology 112 (2006), pp. 74-80.

Christie et al., $2004 \bullet$ P. J. Christie, D. J. Mennill, and L. M. Ratcliffe, Pitch shifts and song structure indicate male quality in the dawn chorus of black-capped chickadees, Behavioral Ecology and Sociobiology 55 (2004), pp. 341-348.

Clark, $2009 \bullet$ C. J. Clark, Courtship dives of Anna's hummingbird offer insights into flight performance limits, Proceedings of the Royal Society B 276 (2009), pp. 3047-3052.

Clark and Feo, $2008 \bullet$ C. J. Clark and T. J. Feo, The Anna's hummingbird chirps with its tail: a new mechanism of sonation in birds, Proceedings of the Royal Soci ety B 275 (2008), pp. 955-962.

Clutton-Brock and McAuliffe, $2009 \bullet$ T. Clutton-Brock and K. McAuliffe, Fe male mate choice in mammals, Quarterly Review of Biology 84 (2009), pp. 3-27.

Coleman et al., $2007 \bullet$ S. W. Coleman, G. L. Patricelli, B. Coyle, J. Siani, and G. Borgia, Female preferences drive the evolution of mimetic accuracy in male sexual displays, Biology Letters 3 (2007), pp. 463-466.

Cooper, $1990 \bullet$ S. M. Cooper, The hunting behavior of spotted hyaenas (Crocuta crocruta) in a region containing both sedentary and migratory populations of herbivores, African Journal of Ecology 28 (1990), pp. 131-141.

Costa and Macedo, $2005 \bullet$ F. J. V. Costa and R. H. Macedo, Coccidian oocyst parasitism in the blue-black grassquit: influence on secondary sex ornaments and body condition, Animal Behaviour 70 (2005), pp. 1401-1409.

Cox and LeBoeuf, $1977 \bullet$ C. R. Cox and B. J. LeBoeuf, Female incitation of male competition: mechanism in sexual selection, American Naturalist 111 (1977), pp. $317-335$. 
Cronin, $1991 \bullet$ H. Cronin, The Ant and the Peacock: Altruism and Sexual Selection from Darwin to Today, Cambridge University Press, Cambridge (1991).

Darwin, $1859 \bullet$ C. R. Darwin, On the Origin of Species by Means of Natural Selection, or the Preservation of Favoured Races in the Struggle for Life, J. Murray, London (1859).

Darwin, $1871 \bullet$ C. R. Darwin, The Descent of Man, and Selection in Relation to Sex, J. Murray, London (1871)

Delaney et al., $2007 \bullet$ K. J. Delaney, J. A. Roberts, and G. W. Uetz, Male signaling behavior and sexual selection in a wolf spider (Araneae: Lycosidae): a test for dual functions, Behavioral Ecology and Sociobiology 62 (2007), pp. 67-75.

Demary et al., $2006 \bullet$ K. Demary, C. I. Michaelidis, and S. M. Lewis, Firefly court ship: behavioral and morphological predictors of male mating success in Pho tinus greeni, Ethology 112 (2006), pp. 485-492.

Deutsch, 1994 • J. C. Deutsch, Lekking by default: female habitat preferences and male strategies in Uganda kob, Journal of Animal Ecology 63 (1994), pp. 101-115.

Doall et al., $1998 \bullet$ M. H. Doall, S. P. Colin, J. R. Strickler, and J. Yen, Locating a mate in 3D: the case of Temora longicornis, Philosophical Transactions of the Royal Society B 353 (1998), pp. 681-689.

Downes, $1969 \bullet$ J. A. Downes, The swarming and mating flight of Diptera, Annual Review of Entomology 14 (1969), pp. 271-298.

Draganoiu et al., 2002 • T. I. Draganoiu, L. Nagle, and M. Kreutzer, Directional female preference for an exaggerated male trait in canary (Serinus canaria) song, Proceedings of the Royal Society B 269 (2002), pp. 2525-2531.

Emlen, $2008 \bullet$ D. J. Emlen, The evolution of animal weapons, Annual Review of Ecology Evolution and Systematics 39 (2008), pp. 387-413.

Fernandez and Morris, $2007-$ A. A. Fernandez and M. R. Morris, Sexual selec tion and trichromatic color vision in primates: statistical support for the pre existing-bias hypothesis, American Naturalist 170 (2007), pp. 10-20.

Fisher, $1930 \bullet$ R. A. Fisher, The Genetical Theory of Natural Selection, Clarendon, Ox ford (1930).

FitzGibbon and Fanshawe, 1988 - C. D. FitzGibbon and J. H. Fanshawe, Stot ting in Thomson's gazelles: an honest signal of condition, Behavioral Ecology and Sociobiology 23 (1988), pp. 69-74.

Foelix, $1996 \bullet$ R. Foelix, Biology of Spiders (2nd edn), Oxford University Press, New York (1996)

Foreman et al., $1997 \bullet$ N. Foreman, A. Fielder, C. Minshell, and E. Hurrion, Visual search, perception, and visual-motor skill in "healthy" children born at 27-32 weeks' gestation, Journal of Experimental Child Psychology 64 (1997), pp. 27-41.

Framenau and Hebets, $2007 \bullet$ V. W. Framenau and E. A. Hebets, A review of leg ornamentation in male wolf spiders, with the description of a new species from Australia, Artoria schizocoides (Araneae, Lycosidae), Journal of Arachnology 35 (2007), pp. 89-101.

Gibson and Uetz, $2008 \bullet$ J. S. Gibson and G. W. Uetz, Seismic communication and mate choice in wolf spiders: components of male seismic signals and mat ing success, Animal Behaviour 75 (2008), pp. 1253-1262.

Gil and Gahr, $2002 \bullet$ D. Gil and M. Gahr, The honesty of bird song: multiple con straints for multiple traits, Trends in Ecology e Evolution 17 (2002), pp. 133-141.

Hasselquist et al., $1996 \bullet$ D. Hasselquist, S. Bensch, and T. vonSchantz, Correla tion between male song repertoire, extra-pair paternity and offspring survival in the great reed warbler, Nature 381 (1996), pp. 229-232.

Hebets and Uetz, $1999 \bullet$ E. A. Hebets and G. W. Uetz, Female responses to iso lated signals from multimodal male courtship displays in the wolf spider ge nus Schizocosa (Araneae: Lycosidae), Animal Behaviour 57 (1999), pp. 865-872.

Hebets and Uetz, $2000 \bullet$ E. A. Hebets and G. W. Uetz, Leg ornamentation and the efficacy of courtship display in four species of wolf spider (Araneae: Lycosidae), Behavioral Ecology and Sociobiology 47 (2000), pp. 280-286.

Hedrick, $1986 \bullet$ A. V. Hedrick, Female preferences for male calling bout duration in a field cricket, Behavioral Ecology and Sociobiology 19 (1986), pp. 73-77.

Hill, $1990 \bullet$ G. E. Hill, Female house finches prefer colorful males: sexual selec tion for a condition-dependent trait, Animal Behaviour 40 (1990), pp. 563-572.

Hoefler et al., 2008 C. D. Hoefler, M. H. Persons, and A. L. Rypstra, Evolution arily costly courtship displays in a wolf spider: a test of viability indicator theory, Behavioral Ecology 19 (2008), pp. 974-979.

Hoefler et al., $2009 \bullet$ C. D. Hoefler, A. L. Carlascio, M. H. Persons, and A. L. Rypstra, Male courtship repeatability and potential indirect genetic benefits in a wolf spider, Animal Behaviour 78 (2009), pp. 183-188

Hogg, $1984 \bullet$ J. T. Hogg, Mating in bighorn sheep: multiple creative male strate gies, Science 225 (1984), pp. 526-529.

Hogg and Forbes, $1997 \bullet$ J. T. Hogg and S. H. Forbes, Mating in bighorn sheep: frequent male reproduction via a high-risk 'unconventional' tactic, Behavioral Ecology and Sociobiology 41 (1997), pp. 33-48.

Hoglund and Lundberg, $1987 \bullet$ J. Hoglund and A. Lundberg, Sexual selection in a monomorphic lek-breeding bird: correlates of male mating success in the breat snipe Gallinago media, Behavioral Ecology and Sociobiology 21 (1987), pp. $211-216$

Holekamp et al., 1997 - K. E. Holekamp, L. Smale, R. Berg, and S. M. Cooper, Hunting rates and hunting success in the spotted hyena (Crocuta crocuta), Journal of Zoology 242 (1997), pp. 1-15.

Holland and Rice, 1998 B. Holland and W. R. Rice, Perspective: chase away sexual selection: antagonistic seduction versus resistance, Evolution 52 (1998), pp. 1-7.
Houle and Kondrashov, 2002 D. Houle and A. S. Kondrashov, Coevolution of costly mate choice and condition-dependent display of good genes, Proceedings of the Royal Society B 269 (2002), pp. 97-104

Irschick et al., 2007 D. J. Irschick, A. Herrel, B. Vanhooydonck, and R. Van Damme, A functional approach to sexual selection, Functional Ecology 21 (2007), pp. 621-626.

Isvaran and Jhala, 2000 K. Isvaran and Y. Jhala, Variation in lekking costs in blackbuck (Antilope cervicapra): relationship to lek-territory location and female mating patterns, Behaviour 137 (2000), pp. 547-563

Johnsgard, $1997 \bullet$ P. A. Johnsgard, The Hummingbirds of North America (2nd edn), Smithsonian Institution Press, Washington, D. C. (1997).

Kirkpatrick, $1982 \bullet$ M. Kirkpatrick, Sexual selection and the evolution of female choice, Evolution 36 (1982), pp. 1-12

Kirkpatrick, $1987 \bullet$ M. Kirkpatrick, Sexual selection by female choice in polygy nous animals, Annual Review of Ecology and Systematics 18 (1987), pp. 43-70.

Kokko et al., $1999 \bullet$ H. Kokko, P. T. Rintamaki, R. V. Alatalo, J. Hoglund, E. Kar vonen, and A. Lundberg, Female choice selects for lifetime lekking perfor mance in black grouse males, Proceedings of the Royal Society B 266 (1999), pp. 2109-2115.

Kotiaho and Puurtinen, $2007 \bullet$ J. S. Kotiaho and M. Puurtinen, Mate choice for indirect genetic benefits: scrutiny of the current paradigm, Functional Ecology 21 (2007), pp. 638-644

Kotiaho et al., 1998a • J. Kotiaho, R. V. Alatalo, J. Mappes, S. Parri, and A. Rivero Male mating success and risk of predation in a wolf spider: a balance between sexual and natural selection?, Journal of Animal Ecology 67 (1998), pp. 287-291.

Kotiaho et al., 1998b - J. S. Kotiaho, R. V. Alatalo, J. Mappes, M. G. Nielsen, S. Parri, and A. Rivero, Energetic costs of size and sexual signalling in a wolf spider, Proceedings of the Royal Society B 265 (1998), pp. 2203-2209.

Kotiaho et al., $1999 \bullet$ J. S. Kotiaho, R. V. Alatalo, J. Mappes, and S. Parri, Sexual signalling and viability in a wolf spider (Hygrolycosa rubrofasciata): measurements under laboratory and field conditions, Behavioral Ecology and Sociobiology 46 (1999), pp. 123-128.

Kruuk, $1972 \bullet$ H. Kruuk, The Spotted Hyena: a Study of Predation and Social Behavior, University of Chicago Press, Chicago (1972)

Lambrechts, $1996 \bullet$ M. M. Lambrechts, Organization of birdsong and constraints on performance. In: D. E. Kroodsma and E. H. Miller, editors, Ecology and Evolution of Acoustic Communication in Birds, Cornell University Press, Ithaca, New York (1996), pp. 305-320

Land, $1993 \bullet$ M. F. Land, The visual control of courtship behavior in the fly Poeci lobothrus nobilitatus, Journal of Comparative Physiology A 173 (1993), pp. 595-603.

Land and Collett, $1974 \bullet$ M. F. Land and T. S. Collett, Chasing behavior of house flies (Fannia canicularis): description and analysis, Journal of Comparative Physiol ogy 89 (1974), pp. 331-357.

Lande, $1981 \bullet$ R. Lande, Models of speciation by sexual selection on poly genic traits, Proceedings of the National Academy of Sciences, U. S. A. 78 (1981), pp $3721-3725$.

Larimer and Dudley, 1995 • J. L. Larimer and R. Dudley, Accelerational implica tions of hummingbird display dives, Auk 112 (1995), pp. 1064-1066.

Leuthold, $1966 \bullet$ W. Leuthold, Variations in territorial behavior of Uganda kob Adenota kob thomasi (Neumann 1896), Behaviour 27 (1966), pp. 214-257.

Lewis and Cratsley, $2008 \bullet \mathrm{S}$. M. Lewis and C. K. Cratsley, Flash signal evolution, mate choice, and predation in fireflies, Annual Review of Entomology 53 (2008), pp. 293-321.

Lindström et al., 2006 L. Lindström, J. J. Ahtiainen, J. Mappes, J. S. Kotiaho, A Lyytinen, and R. V. Alatalo, Negatively condition dependent predation cost of a positively condition dependent sexual signalling, Journal of Evolutionary Biol ogy 19 (2006), pp. 649-656.

Lomborg and Toft, $2009 \bullet$ J. P. Lomborg and S. Toft, Nutritional enrichment in creases courtship intensity and improves mating success in male spiders, Be havioral Ecology 20 (2009), pp. 700-708.

Lott, 2002 D. F. Lott, American Bison: a Natural History, University of California Press, Berkeley (2002)

Lunau, 1992 K. Lunau, Limits of color learning in a flower-visiting hoverfly, Eri stalis tenax L. (Syrphidae, Diptera), European Journal of Neuroscience, Supplement 5 (1992), p. 103

Mappes et al., $1996 \bullet$ J. Mappes, R. V. Alatalo, J. Kotiaho, and S. Parri, Viability costs of condition-dependent sexual male display in a drumming wolf spider, Proceedings of the Royal Society B 263 (1996), pp. 785-789.

Martin et al., $2006 \bullet$ J. Martin, L. de Neve, V. Polo, J. A. Fargallo, and M. Soler, Health-dependent vulnerability to predation affects escape responses of unguarded chinstrap penguin chicks, Behavioral Ecology and Sociobiology 60 (2006), pp. 778-784.

Mather and Robertson, $1992 \bullet$ M. H. Mather and R. J. Robertson, Honest adver tisement in flight displays of bobolinks (Dolichonyx oryzivorus), Auk 109 (1992), pp. 869-873

Matsumasa and Murai, 2005 - M. Matsumasa and M. Murai, Changes in blood glucose and lactate levels of male fiddler crabs: effects of aggression and claw waving, Animal Behaviour 69 (2005), pp. 569-577.

Mills, 1990 - M. G. L. Mills, Kalahari Hyaenas: the Behavioural Ecology of Two Species, Unwin Hyman, London (1990) 
Møller, $1991 \bullet$ A. P. Møller, Male tail length and female mate choice in the monog amous swallow Hirundo rustica, Animal Behaviour 39 (1991), pp. 458-465.

Murai and Backwell, $2006 \bullet$ M. Murai and P. R. Y. Backwell, A conspicuous courtship signal in the fiddler crab Uca perplexa: female choice based on display structure, Behavioral Ecology and Sociobiology 60 (2006), pp. 736-741.

Norberg, $1991 \bullet$ R. A. Norberg, The flappet lark Mirafra rufocinnamomea doubles its wingbeat to $24 \mathrm{~Hz}$ in wing-clap display flight: a sexually selected feat, Journal of Experimental Biology 159 (1991), pp. 515-523.

Nowicki, $1987 \bullet$ S. Nowicki, Vocal-tract resonances in oscine bird sound production: evidence from birdsongs in a helium atmosphere, Nature 325 (1987), pp. 53-55.

Nowicki et al., $1998 \bullet$ S. Nowicki, S. Peters, and J. Podos, Song learning, early nutrition and sexual selection in songbirds, American Zoologist 38 (1998), pp. 179-190.

Nowicki et al., $2002 \bullet$ S. Nowicki, W. A. Searcy, and S. Peters, Brain development, song learning and mate choice in birds: a review and experimental test of the 'nutritional stress hypothesis', Journal of Comparative Physiology A 188 (2002), pp. 1003-1014.

Parri et al., 2002 - S. Parri, R. V. Alatalo, J. S. Kotiaho, J. Mappes, and A. Rivero, Sexual selection in the wolf spider Hygrolycosa rubrofasciata: female preference for drum duration and pulse rate, Behavioral Ecology 13 (2002), pp. 615-621.

Pelletier et al., $2004 \bullet$ F. Pelletier, J. T. Hogg, and M. Festa-Bianchet, Effect of chemical immobization on social status of bighorn rams, Animal Behaviour 67 (2004), pp. 1163-1165.

Peterson and Ciucci, $2003 \bullet$ R. O. Peterson and P. Ciucci, The wolf as a carni vore. In: L. D. Mech and L. Boitani, editors, Wolves: Behavior, Ecology, and Conser vation, University of Chicago Press, Chicago (2003), pp. 104-130.

Petrie, $1994 \bullet$ M. Petrie, Improved growth and survival of offspring of peacocks with more elaborate trains, Nature 371 (1994), pp. 598-599.

Podos, $1996 \bullet \mathrm{J}$. Podos, Motor constraints on vocal development in a songbird, Animal Behaviour 51 (1996), pp. 1061-1070.

Podos, $1997 \bullet$ J. Podos, A performance constraint on the evolution of trilled vocal izations in a songbird family (Passeriformes:Emberizidae), Evolution 51 (1997), pp. 537-551.

Podos and Nowicki, $2004 \bullet$ J. Podos and S. Nowicki, Performance limits on birdsong. In: P. Marler and H. Slabbekoorn, editors, Nature's Music: the Science of Birdsong, Elsevier Academic Press, San Diego (2004), pp. 318-342.

Podos et al., $2009 \bullet$ J. Podos, D. C. Lahti, and D. L. Moseley, Vocal performance and sensorimotor learning in songbirds, Advances in the Study of Behavior 40 (2009), pp. 159-196.

Poesel et al., $2001 \bullet$ A. Poesel, K. Foerster, and B. Kempenaers, The dawn song of the blue tit Parus caeruleus and its role in sexual selection, Ethology 107 (2001), pp. 521-531.

Pomiankowski and Møller, $1995 \bullet$ A. Pomiankowski and A. P. Møller, A resolu tion of the lek paradox, Proceedings of the Royal Society B 260 (1995), pp. 2l-29.

Prestwich, $1994 \bullet$ K. N. Prestwich, The energetics of acoustic signaling in an urans and insects, American Zoologist 34 (1994), pp. 625-643.

Prestwich and O'Sullivan, $2005 \bullet$ K. N. Prestwich and K. O'Sullivan, Simultaneous measurement of metabolic and acoustic power and the efficiency of sound production in two mole cricket species (Orthoptera: Gryllotalpidae), Journal of Experimental Biology 208 (2005), pp. 1495-1512.

Prum, 1990 • R. O. Prum, Phylogenetic analysis of the evolution of display behavior in the Neotropical manakins (Aves, Pipridae), Ethology 84 (1990), pp. 202-231.

Prum, $1997 \bullet$ R. O. Prum, Phylogenetic tests of alternative intersexual selection mechanisms: trait macroevolution in a polygynous clade (Aves: Pipridae), American Naturalist 149 (1997), pp. 668-692.

Prum and Johnson, $1987 \bullet$ R. O. Prum and A. E. Johnson, Display behavior, for aging ecology, and systematics of the golden-winged manakin (Masius chrysop terus), Wilson Bulletin 99 (1987), pp. 521-539.

Quinn and Cresswell, 2004 J. L. Quinn and W. Cresswell, Predator hunting behaviour and prey vulnerability, Journal of Animal Ecology 73 (2004), pp. 143-154.

Reid et al., $2004 \bullet$ J. M. Reid, P. Arcese, A. Cassidy, S. M. Hiebert, J. N. M. Smith, P. K. Stoddard, A. B. Marr, and L. F. Keller, Song repertoire size predicts ini tial mating success in male song sparrows, Melospiza melodia, Animal Behaviour 68 (2004), pp. 1055-1063

Riede et al., $2006 \bullet$ T. Riede, R. A. Suthers, N. H. Fletcher, and W. E. Blevins, Songbirds tune their vocal tract to the fundamental frequency of their song, Proceedings of the National Academy of Sciences, U. S. A. 103 (2006), pp. 5543-5548.

Rowe and Houle, $1996 \bullet$ L. Rowe and D. Houle, The lek paradox and the capture of genetic variance by condition dependent traits, Proceedings of the Royal Society B 263 (1996), pp. 1415-1421.

Ryan and Keddy-Hector, $1992 \bullet$ M. J. Ryan and A. Keddy-Hector, Directional patters of female mate choice and the role of sensory biases, American Natural ist, Supplement 139 (1992), pp. S4-S35.
Rypstra et al., 2003 A. L. Rypstra, C. Wieg, S. E. Walker, and M. H. Persons, Mutual mate assessment in wolf spiders: differences in the cues used by males and females, Ethology 109 (2003), pp. 315-325.

Salmon et al., $1978 \bullet$ M. Salmon, G. Hyatt, K. McCarthy, and J. D. Costlow, Display specificity and reproductive isolation in the fiddler crabs, Ucs panacea and Uca pugilator, Zeitschrift für Tierpsychologie 48 (1978), pp. 251-276.

Schaller, $1972 \bullet$ G. B. Schaller, The Serengeti Lion. A Study of Predator-Prey Relations, University of Chicago Press, Chicago (1972)

Schmidt et al., $2008 \bullet$ R. Schmidt, H. P. Kunc, V. Amrhein, and M. Naguib, Ag gressive responses to broadband trills are related to subsequent pairing suc cess in nightingales, Behavioral Ecology 19 (2008), pp. 635-641.

Scholes, $2008 \bullet$ E. Scholes, Evolution of the courtship phenotype in the bird of paradise genus Parotia (Aves: Paradisaeidae): homology, phylogeny, and modularity, Biological Journal of the Linnean Society 94 (2008), pp. 491-504.

Searcy and Nowicki, $2005 \bullet$ W. A. Searcy and S. Nowicki, The Evolution of Animal Communication: Reliability and Deception in Signalling Systems, Princeton University Press, Princeton, New Jersey (2005)

Shamble et al., $2009 \bullet$ P. S. Shamble, D. J. Wilgers, K. A. Swoboda, and E. A. He bets, Courtship effort is a better predictor of mating success than ornamentation for male wolf spiders, Behavioral Ecology 20 (2009), pp. 1242-1251.

Stiles, $1982 \bullet$ F. G. Stiles, Aggressive and courtship displays of the male Anna's hummingbird, Condor 84 (1982), pp. 208-225.

Stratton, $2005 \bullet$ G. E. Stratton, Evolution of ornamentation and courtship behav ior in Schizocosa: insights from a phylogeny based on morphology (Araneae, Lycosidae), Journal of Arachnology 33 (2005), pp. 347-376.

Suthers, $2004 \bullet$ R. A. Suthers, How birds sing and why it matters. In: P. Marler and H. Slabbekoorn, editors, Nature's Music: the Science of Birdsong, Elsevier Academic Press, San Diego (2004), pp. 272-295.

Sutton, $1981 \bullet$ G. M. Sutton, On aerial and ground displays of the world's snipes, Wilson Bulletin 93 (1981), pp. 457-609.

Székely et al., $2000 \bullet$ T. Székely, J. D. Reynolds, and J. Figuerola, Sexual size di morphism in shorebirds, gulls, and alcids: the influence of sexual and natural selection, Evolution 54 (2000), pp. 1404-1413.

Taylor and Williams, $1981 \bullet$ P. D. Taylor and G. C. Williams, On the modelling of sexual selection, Quarterly Review of Biology 56 (1981), pp. 305-313.

Thery, $1990 \bullet \mathrm{M}$. Thery, Display repertoire and social organization of the white fronted and white-throated manakins, Wilson Bulletin 102 (1990), pp. 123-130.

Tomkins et al., $2004 \bullet$ J. L. Tomkins, J. Radwan, J. S. Kotiaho, and T. Tregenza, Genic capture and resolving the lek paradox, Trends in Ecology \& Evolution 19 (2004), pp. 323-328.

Trivers, $1972 \bullet$ R. L. Trivers, Parental investment and sexual selection. In: B. G. Campbell, editor, Sexual Selection and the Descent of Man, 1871-1971, Aldine, Chi cago (1972), pp. 136-179.

Vehrencamp et al., $1989 \bullet$ S. L. Vehrencamp, J. W. Bradbury, and R. M. Gibson, The energetic cost of display in male sage grouse, Animal Behaviour 38 (1989) pp. 885-896.

Voigt et al., 2001 • C. C. Voigt, O. von Helversen, R. Michener, and T. H. Kunz, The economics of harem maintenance in the sac-winged bat, Saccopteryx bilin eata (Emballonuridae), Behavioral Ecology and Sociobiology 50 (2001), pp. 31-36.

Voigt et al., $2005 \bullet$ C. C. Voigt, G. Heckel, and F. Mayer, Sexual selection favours small and symmetric males in the polygynous greater sac-winged bat Saccopteryx bilineata (Emballonuridae, Chiroptera), Behavioral Ecology and Sociobiology 57 (2005), pp. 457-464

Weissburg et al., $1998 \bullet$ M. J. Weissburg, M. H. Doall, and J. Yen, Following the invisible trail: kinematic analysis of mate-tracking in the copepod Temora lon gicornis, Philosophical Transactions of the Royal Society B 353 (1998), pp. 701-712.

Welch et al., $1998 \bullet$ A. M. Welch, R. D. Semlitsch, and H. C. Gerhardt, Call duration as an indicator of genetic quality in male gray tree frogs, Science 280 (1998), pp. 1928-1930

Whitlock and Agrawal, $2009 \bullet$ M. C. Whitlock and A. F. Agrawal, Purging the genome with sexual selection: reducing mutation load through selection on males, Evolution 63 (2009), pp. 569-582.

Wright et al., $2006 \bullet$ G. J. Wright, R. O. Peterson, D. W. Smith, and T. O. Lemke, Selection of northern Yellowstone elk by gray wolves and hunters, Journal of Wildlife Management 70 (2006), pp. 1070-1078.

Wyman et al., $2008 \bullet$ M. T. Wyman, M. S. Mooring, B. McCowan, M. C. T. Penedo, and L. A. Hart, Amplitude of bison bellows reflects male quality, physical condition and motivation, Animal Behaviour 76 (2008), pp. 1625-1639.

Zimmer et al., $2003 \bullet$ M. Zimmer, O. Diestelhorst, and K. Lunau, Courtship in long-legged flies (Diptera: Dolichopodidae): function and evolution of signals, Behavioral Ecology 14 (2003), pp. 526-530. 